\title{
Örgütsel Adaletin Hastayken İşe Gelme (Presenteeism) Davranışına Etkisi: "Hangi Adalet Türü Presenteizmin Belirleyicisidir?"1
}

\author{
Mesut SOYALIN ${ }^{2}$ ve Gökhan KERSE $^{3}$
}

\section{$\ddot{O} z$}

$\mathrm{Bu}$ araștırmada örgütsel adaletin hastayken ișe gelme (presenteeism) davranıșı üzerindeki etkisi incelenmiștir. Ayrıca araştırmada örgütsel adaletin boyutları olan dağıtım adaletinin, prosedür adaletinin ve etkileşim adaletinin hastayken işe gelme (presenteeism) davranışına etkisi de ele alınmıştır. Araştırma verileri kamu kurumu çalışanları örnekleminden elde edilmiştir. Yapılan analizler sonucunda genel anlamda örgütsel adaletin hastayken işe gelme (presenteeism) davranışını doğru yönde etkilediği gözlenmiştir. Boyutlar bazında ise dağıtım adaleti ve prosedür adaletinin hastayken işe gelme davranışını (presenteeism) anlamlı düzeyde etkilemediği; sadece etkileşim adaleti algısının hastayken işe gelme davranışını (presenteeism) doğru yönde etkilediği tespit edilmiştir. Dolayısıyla örgütsel adalet boyutlarından sadece etkileşim adaletinin hastayken işe gelme (presenteeism) davranışında belirleyici rol üstlendiği görülmüştür. Elde edilen bulguların tümü kültürel yapı da dikkate alınarak tartışılmıştır.

Anabtar Kelimeler:Örgütsel Adalet, Hastayken İşe Gelme, Kamu Çalışanları.

The Effect of Organizational Justice on Presenteeism: "Which Type of Justice is The Determinator of Presenteeism?”

\begin{abstract}
In this study, the effect of organizational justice on presenteeism behavior was examined. The research also examined the effect of distribution justice, procedural justice and interaction justice which are dimensions of organizational justice on presenteeism behavior. Research data were obtained from sample of public institution employees. As a result of the made analyzes, it was observed that organizational justice generally affects the presenteeism behavior in the positive direction. On the dimensions, distribution justice and procedural justice did not significantly affect presenteeism behavior; it has been found that only the interaction justice perception affects the presenteeism in the positive direction. Consequently, it has been seen that only justice of interaction from dimensions of organizational justice has a determinative role in the behavior of presenteeism. All of the findings were discussed considering the cultural structure.
\end{abstract}

Key Words: Organizational Justice, Presenteeism, Public Employees

Atıf İçin / Please Cite As:

Soyalın, M. ve Kerse, G. (2020). Örgütsel adaletin hastayken işe gelme (presenteeism) davranışına etkisi: "Hangi adalet türü presenteizmin belirleyicisidir?”. Manas Sosyal Araştırmalar Dergisi, 9(1), 190-198.

\footnotetext{
${ }^{1}$ Bu çalışma 19-21 Ekim 2018 tarihinde Nevşehir (Kapadokya)'de düzenlenen III. Uluslararası Kaoru Ishikawa İşletme Bilimleri ve Ekonomi Kongresi'nde sunulan bildirinin genişletilmesiyle oluşturulmuştur.

2 Dr. - Siirt Üniversitesi, Kurtalan Meslek Yüksekokulu, İşletme Bölümü, msoyalin@hotmail.com ORCID: 0000-0003-1475-0905.

${ }^{3}$ Doç. Dr. - Karamanoğlu Mehmetbey Üniversitesi, İktisadi ve İdari Bilimler Fakültesi, İşletme Bölümü, gokhankerse@hotmail.com - ORCID: 0000-0002-1565-9110.
} 


\section{Giriş}

Hastayken işe gelme (presenteeism) kavramı çalısanların hasta olmasına veya sağlık şikâyetleri bulunmasına rağmen işten uzaklaşıp dinlenmek yerine işe devam etmeleri olarak tanımlanmaktadır (Aronsson vd., 2000). Çalışanların hastalanarak işe gelmemesi işletmeler açısından verimlilik kaybı nedenlerinden biri olarak görülebilmektedir. Diğer taraftan hasta olunmasına rağmen bir takım sebeplerden dolayı iş yerinde çalışmaya devam edilmesinin ortaya çıkaracağı verimlik kaybı ve işletme maliyetinin çalışmaya devam edilmemesinden kaynaklı zararlardan daha yüksek olacağına yönelik düşünceler de bulunmaktadır. Çalışanların hastayken işe gelme davranışının açıklanmasında birçok faktör olmakla birlikte işini kaybetme korkusu ve işe olan bağlllığın güçlü olması gibi nedenler bu faktörlerden başlıcalarıdır. Bu araştırmada ise hastayken işe gelme davranışının altında yatan nedenlerden birisinin örgütteki adalet algisı olabileceği düşünülmüştür.

Örgütsel adalet algısı örgütsel ortamda çalısanların kendilerine adil olarak davranılıp davranılmadığına yönelik algılarını ifade etmektedir (Greenberg, 1990). Örgütsel adalet algısı çalışanların örgütleri için yapabilecekleri fedakârlıkları etkileyebilmektedir. Bu bağlamda örgütlerindeki ödül, süreç ve uygulamaları adil olarak algılayan çalışanların hastayken işe gelme (presenteeism) davranışı sergileyebilecekleri beklenmektedir.

Bu çalışmada, çalışanların örgüt içerisindeki tutum ve davranışlarında belirleyici rol üstlenen örgütsel adalet algısının hastayken işe gelme (presenteeism) davranışı üzerindeki etkisi incelenmektedir. Çalışmanın teorik bölümünde söz konusu kavramlar açıklanmaktadır. Yöntem kısmında ise öne sürülen hipotezleri test etmek amacıyla gerçekleştirilen alan araştırmasına yer verilmektedir. Bulgular kısmında yapılan analizler sonucu elde edilen sonuçlara yer verilmekte; sonuç kısmında ise ulaşılan bulgular değerlendirilerek gelecek çalısmalar için öneriler sunulmaktadır.

\section{Teorik Çerçeve}

\section{Örgütsel Adalet}

Örgütsel adalet kavramını açılamada örgütsel ortamda adaletlilik algısının ifade edildiği Adams'nn Eşitlik Teorisi (Adams, 1965) yaygın olarak kullanılmaktadır. Teoriye göre çalışanlar ve örgütler karşlıklı olarak sarf ettikleri çaba ile elde ettikleri çıktıyı diğer benzer koşullardaki bireylerle ya da örgütlerle karşılaştırmaktadır. Yapılan karşılaştırma sonucu adaletin veya adaletsizliğin olduğu yargısına varılmakta (Greenberg, 1990), bu durum ise çalışanın tutum ve davranışlarına yansımaktadır.

Örgütsel adalet örgüt içindeki süreç ve uygulamalarda adil ya da adaletli olma durumunu ifade etmektedir (Colquitt vd., 2001). Örgütsel adalet aynı zamanda çalışanların örgüt içindeki uygulamaları, kuralları ve prosedürleri kendilerine göre doğru olarak algılama biçimlerini yansıtmaktadır (Bakan vd., 2017). Bu bağlamda çalışanlar yönetimsel uygulamaları değerlendirmekte ve subjektif olarak adilliğin olup olmadığına karar vermektedir (Cropanzano vd., 2007). Dolayısıyla adalet veya adaletsizlik, algisal olarak belirlenebilmektedir.

Örgütsel adalet ilk yıllarda çıktıların paylaştırılmasına odaklanan "dağıtım adaleti" bakış açısıyla ele alınmıştır (Adams, 1965). Daha sonraki dönemlerde kavram çok boyutlu olarak açıklanmış ve "dağıtım adaleti, prosedür/işlem adaleti ve etkileşim adaleti” olarak 3 boyutta incelenmiştir (Niehoff ve Moorman, 1993). Dağııım adaleti çalışanların örgütte elde ettiği ücret ve terfi gibi çıktılarla ilgili adalet algısını ifade ederken (Cohen-Charas ve Spector, 2001), prosedür adaleti ücret, terfi ve performans değerleme gibi faktörlerin belirlenmesinde kullanılan süreç ve politikaların adil olma düzeyini ifade etmektedir (Greenberg, 1990). Etkileşim adaleti ise örgütlerde bireyler arası ilişkilerin ve davranışların adil olmasıdır (Yıldız, 2014). Etkileşim adaleti kişilerarası adalet ve bilgisel adalet algılarının birleşiminden oluşmaktadır. Kişilerarası adalet yöneticilerin çalışanlara nezaket ve sayg1 çerçevesinde davranmasını ve onları rencide etmekten kaçınmasını içerirken; bilgisel adalet ise karar verme sürecindeki prosedürler hakkında çalışanlara bilgiler verilmesini içermektedir (Colquitt vd., 2001).

Örgüt içinde adalet algısı, bireylerin kendilerine karşı adil olunup olunmadığını gözlemlemeleri ve bu doğrultuda tutum geliştirmelerini sağlamaktadır (Greenberg, 1990). Adaletin algılanmasıyla örgütsel bağlamda çalışanın örgüte güveni (Rajabi vd., 2017), bağlılı̆̆1 (Çağlıvan vd., 2017) ve vatandaşlık davranışı (Samancı ve Basım, 2018) güçlenmekte, sinizmi ise azaltmaktadır (Güzel ve Ayazlar, 2014). Adaletin 
algılanması iş bağlamında ise iş tatminini, iş performansını (Atlaş ve Çekmecelioğlu, 2015) ve işe bağlanmayı (Lyu, 2016) artırmaktadır.

\section{Hastayken İşe Gelme (Presenteeism)}

Ulusal yazında "işte varolmama" (Baysal vd., 2014) ve "hastayken işe gelme" kavramıyla karşllı bulan presenteeism kavramı iki farklı bakış açısıyla ele alınabilir. İlk bakış açısına göre presenteeism bağllığın sapkın bir göstergesidir; ve iş güvensizliğinin rahatsız ediciliğinden kurtulmak için iş saatlerinde aşırllı̆ga ulaşmak yani çok fazla çalışabilmektir (Lowe, 2002). İkinci bakış açısına göre ise hasta olmasına veya sağlık şikâyetleri bulunmasına rağmen işten uzaklaşıp dinlenmek yerine hala işe devam etmek olarak tanımlanmaktadır (Aronsson vd., 2000). Presenteeism çalışanların hasta oldukları halde işe gelmeleri ve işyerinde boşa zaman geçirmeleridir (Demirgil ve Mücevher, 2017).

Dew ve arkadaşlarına göre (2005) çalışanın hastayken işe gelmesi (presenteeism) aldığı rasyonel kararların bir sonucudur ve bu durum işyerine ve yaptıkları işin içeriğine göre farklılaşmaktadır. Örneğin çalışanların hasta olmasına rağmen işe gelme kararını vermesi sağlık ve eğitim gibi sektörlerde diğer sektörlere oranla daha yüksek düzeyde gerçekleşmektedir (Aronsson vd., 2000). Çünkü bu sektörlerdeki bireyler kendi görevlerinin yerine başkalarını koymakta zorlanmaktadır ve bu nedenle de sağlık sorunları olsa bile işe gitme zorunluluğu hissetmektedir (Çiftçi, 2010). Bununla birlikte söz konusu durumun özel sektörde aşırı rekabetin olması nedeniyle bu sektörde faaliyet gösteren işletmeler arasında daha sık görülmesi de oldukça olasıdır (Demirbulat ve Bozok, 2015).

Hastayken işe gelme (presenteeism) kavramı araştırmacilar tarafindan "sickness absenteeism (hastalık nedeniyle gelmeme)" kavramının tam zittı olarak da kullanılmaktadır (Prater ve Smith, 2011). Hastayken işe gelme, hastalık nedeniyle gelmemenin tam zıttı olması nedeniyle olumlu bir alg1 ortaya çıkarsa da örgüt ve çalışan açısından bazı olumsuz sonuçlara neden olabilmektedir. Sağlık sorunlarının artması, çalışma yaşamının kalitesine zarar vermesi ve verimliliği azaltması gibi sonuçlar bu olumsuz durumlardan bazılarıdır (Johns, 2010). Ayrıca hastayken işe gelme sonucunda ortaya çıkan çalışanın işindeki yetersizliği ve işini gereğince yerine getirememesi, müşteri tatminsizliği gibi telafisi olmayan veya olsa bile uzun süreyi kapsayacak olumsuzluklara neden olmaktadır (Çetin, 2016). Sağlık sorunları olmasına rağmen işe gelme davranışı göstermek çalışan açısından ise kariyer beklentisi doğrultusunda yapılan bir davranış olarak algılanıp, çalışanların iş arkadaşlarına psikolojik baskı yapmasına yol açabilmektedir (Conway vd. 2016). Öte yandan tüm bu olumsuz sonuçlanına rağmen hasteyken işe gelme davranışının etkili bir şekilde yönetilmesiyle rekabet avantaj1 elde etmek mümkün olabilir (Hemp, 2004; Johns, 2010).

\section{Araştırma Hipotezleri}

Literatürde örgütsel adalet ile hastayken işe gelme (presenteeism) davranışı arasındaki ilişkiyi ele alan araştırmalar oldukça sınırlıdır. Konuyla ilgili Akdoğan, Harmancı ve Bayram (2018) adalet algısının mesleki stres aracıllğı ile hastayken işe gelme (presenteeism) davranışını etkileyeceği yönünde model oluşturmuştur. Kayseri'de farklı işletmelerdeki mavi yakalılar üzerinde yapılan araştırmada örgütsel adaletin hastayken işe gelme (presenteeism) üzerinde pozitif yönde bir etkisinin olduğu görülmüştür. Ayrıca bulgular örgütsel adaletin hastayken işe gelme (presenteeism) üzerindeki etkisinde mesleki stresin tam arac1 rol üstlendiğini göstermiştir.

$\mathrm{Bu}$ araştırmada da bu bulgu doğrultusunda kamu kurumu örnekleminde adalet algısının hastayken işe gelme (presenteeism) davranışını olumlu yönde etkileyeceği beklenmektedir. Araştırmada etkisellik hem genel adalet algisı hem de boyutlar bazında incelenmiş ve aşağıda oluşturulan hipotez(ler) test edilmeye çalısıllmıştır:

\section{H1: Kamu kurumu çalısanlanını adalet alg1sı, hastayken işe gelme (presenteeism) davranısinı olumlu yönde etkiler.}

H1 a: Kamu kurumu çalşanlarmn dağıtım adaleti algısı, bastaykeen işe gelme (presenteeism) davramışın olumlu yönde etkiler.

H1b: Kamu kurumu çalışanlarmm prosedür adaleti algısi, hastayken işe gelme (presenteeism) davramısım olumlu yönde etkiler.

H1c: Kamu kurumu çalışanlarmm etkileşim adaleti algısı, hastayken işe gelme (presenteeism) davranışım olumlu yönde etkiler. 


\section{Araştırmanın Kapsamı ve Yöntemi}

Araştırmanın ana kütlesini Siirt ilindeki bir kamu kuruluşunda hizmet veren 140 personel oluşturmaktadır. Araştırma evreninden $\% 95$ güven düzeyinde $\% 5$ lik bir hata öngörülerek seçilecek örneklem büyüklügü 103 olarak belirlenmiştir. Kamu kuruluşlarına gönderilen 110 anketten (elden ve email yoluyla) 104 tanesi hatasız ve eksiksiz doldurulmuş olarak geri dönmüss (geri dönüş oranı \%94,5) ve 104 anket üzerinde analizler gerçekleştirilmiştir. Veriler SPSS 18.0 istatistik paket programı kullanılarak analiz edilmiştir.

Araştırmada veri toplamak için anket tekniğinden yararlanılmıştır. Hazırlanan anket formu 3 bölümden oluşmakta olup toplam 31 madde içermektedir. İlk bölümde yer alan 5 madde demografik özellikleri (cinsiyet, yaş, medeni durum, eğitim durumu ve deneyim süresi) ölçmeye yöneliktir. Anketin ikinci ve üçüncü bölümünde ise örgütsel adalet ve hastayken işe gelme (presenteeism) ile ilgili ifadeler yer almaktadır. Örgütsel adalet algısı için Niehoff ve Moorman (1993) tarafindan geliştirilen 20 soruluk ölçek; Hastayken işe gelme (presenteeism) için ise Koopman ve arkadaşlanı (2002) tarafindan geliştirilen 6 soruluk ölçek kullanılmıştır. Ölçeklerde yer alan 26 madde, 5’li Likert Ölçeği (1-Kesinlikle Katılmıyorum......5Kesinlikle Kat1liyorum) ile ölçülmüştür.

\section{Bulgular}

\section{Demografik Bulgular}

Araştırmaya katılan kamu kurumu çalışanlarına ilişskin demografik bulgular Tablo 1'de sunulmuştur.

Tablo 1. Katıllma Callşanlara İliskkin Demografik Bulgular

\begin{tabular}{|c|c|c|c|}
\hline Değisken & Kategori & Frekans & $(\%)$ \\
\hline \multirow{2}{*}{ Cinsiyet } & Erkek & 61 & 58,1 \\
\hline & Kadın & 43 & 41,3 \\
\hline \multirow{2}{*}{ Medeni Durum } & Evli & 39 & 37,1 \\
\hline & Bekâr & 65 & 61,9 \\
\hline \multirow{3}{*}{ Yaş } & 1946-1964 & 1 & 1 \\
\hline & 1964-1980 & 13 & 12,5 \\
\hline & $1980-2000$ & 90 & 86,5 \\
\hline \multirow{4}{*}{ Ĕğitim Durumu } & Lise veya alt1 & 15 & 14,4 \\
\hline & Önlisans & 48 & 46,2 \\
\hline & Lisans & 36 & 34,6 \\
\hline & Lisansüstü & 5 & 4,8 \\
\hline \multirow{4}{*}{ Çalışma Süresi } & 1 yildan az & 32 & 30,8 \\
\hline & $1-4 \mathrm{y} 1 \mathrm{l}$ & 24 & 23,1 \\
\hline & $5-8$ & 28 & 26,9 \\
\hline & 9 yil üzeri & 20 & 19,2 \\
\hline
\end{tabular}

Tablo 1'e bakıldığında kamu çalışanlarının çoğunun erkek olduğu $(\% 41,3)$ ve bekâr $(\% 61,9)$ bireylerden oluştuğu görülmektedir. Tabloya göre; 30 yaş altındaki çalışanlar sayıca fazladır (\%86,5). Çalışanların geneli ön lisans $(\% 46,2)$ eğitim düzeyindeki bireylerden oluşmaktadır. Çalışma süresi açısından ise 1 yıldan az $(\% 30,8)$ çalışan bireylerin sayıca fazlalı̆̆ gözlenmektedir.

\section{Ölçeklere İlişkin Faktör Analizi Bulguları}

Çalışmada kullanılan ölçekteki ifadelerin uygun boyutlar altında toplanmasını sağlamak için açılayıcı faktör analizi yapılmıştır. Katılımcıların yeterliliği ve verilerin anlamlılığı için örgütsel adalet ve hastayken işe gelme (presenteeism) davranışına ait ölçeklerde KMO'nun 0,60'dan yüksek ve Barlett Küresellik Testinin anlamlılı̆ının da 0,000 olması dikkate alınmıştır. Örgütsel destek algısı ölçeğine yapılan açıklayıcı faktör analizi bulguları Tablo 2' de verilmiştir. 
Tablo 2. Örgütsel Adalet Ölçegine Ilişkin Faktör Analizi

\begin{tabular}{|c|c|c|c|}
\hline Sorunun Sira Numaras1 & $F 1$ & $F 2$ & $F 3$ \\
\hline $\begin{array}{l}\text { Dağıtım Adaleti } \\
\text { DA2. } \\
\text { DA4. } \\
\text { DA1. } \\
\text { DA3. } \\
\text { DA5. }\end{array}$ & $\begin{array}{l}, 856 \\
, 717 \\
, 671 \\
, 653 \\
567\end{array}$ & & \\
\hline $\begin{array}{l}\text { Prosedürel Adalet } \\
\text { PA8. } \\
\text { PA7. } \\
\text { PA9. } \\
\text { PA11. } \\
\text { PA6. }\end{array}$ & & $\begin{array}{l}, 815 \\
, 769 \\
, 618 \\
, 614 \\
, 462\end{array}$ & \\
\hline $\begin{array}{l}\text { Etkileşim Adaleti } \\
\text { EA14. } \\
\text { EA12. } \\
\text { EA.16. } \\
\text { EA.15. } \\
\text { EA.19. } \\
\text { EA.13. } \\
\text { EA.18. } \\
\text { EA.20. } \\
\text { EA.17. }\end{array}$ & & & $\begin{array}{l}803 \\
, 779 \\
, 771 \\
, 760 \\
, 745 \\
, 692 \\
637 \\
, 580 \\
, 560\end{array}$ \\
\hline $\begin{array}{l}\text { Açılklanan VaryansYüzdesi } \\
\text { Toplam Varyans Yüzdesi }\end{array}$ & $\begin{array}{l}18,173 \\
18,173\end{array}$ & $\begin{array}{l}20,092 \\
38,265\end{array}$ & $\begin{array}{l}31,201 \\
69,466\end{array}$ \\
\hline
\end{tabular}

Açıklayıcı faktör analizinde örgütsel adalet ölçeğinin Kaiser-Meyer Olkin (KMO) değeri 0,933 olması verilerin faktör analizine uygunluğunu; Bartlett küresellik testi oranının (Bartlett test of sphericity), 000 olması verilerden anlamlı faktörler çıkacağını göstermiştir (Tablo 2'de görülebilir). Analiz sonucunda değişkenlere yüklenen maddeler orjinal ölçekteki değişkenlere yüklenen maddelerle benzer dağılım göstermiştir. Öte yandan analizde iki faktöre birden yüklenen ve bu yükler arasındaki farkın 0,10'dan daha az olduğu bir madde analizden çıkarılmıştır. Son durumda 3 boyut (dağıtım adaleti, prosedür adaleti ve etkileşim adaleti) elde edilmiş, faktör yükleri 0,462 ile 0,856 arasında değerler almıştır. Öte yandan analizde ölçeğin toplam varyansın \%69,466'sını açıkladığı belirlenmiştir. Ölçekteki boyutlara ilişkin Cronbach Alfa güvenilirlik katsayısı sırasıyla 0,$687 ; 0,710$ ve 0,779 bulunmuştur.

Hastayken işe gelme davranışı ölçeğine ilişkin açıklayıcı faktör analizi bulguları Tablo 3'de sunulmuştur.

Tablo 3. Hastayken Isse Gelme (Presenteeism) Ölçeğine İlişkin Faktör Analiz̨i

\begin{tabular}{lc}
\hline Sorunun Sira Numarasi & F1 \\
\hline Hastayken İșe Gelme (Presenteeism) &, 857 \\
P4. &, 855 \\
P5. &, 854 \\
P6. &, 794 \\
P2. &, 773 \\
P3. &, 673 \\
P1. &, 673 \\
\hline
\end{tabular}

Açıklanan Varyans Yüzdesi

64,581

Hastayken işe gelme (presenteeism) ölçeğine ilişkin faktör analizinde Kaiser Meyer-Olkin (KMO) değeri 0,889, Bartlett küresellik testi oranının (Bartlett test of sphericity) 323,448 olması verilerin uygunluğunu ve anlamlllı̆ını ifade etmektedir (Tablo 3). Analiz sonucunda değişkenlere yüklenen maddeler orjinal ölçekteki değişkenlere yüklenen maddelerle benzer dağıllım göstermiştir. Toplam 6 maddeye yapılan analiz sonucunda tek boyut elde edilmiş ve faktör yükleri 0,673 ile 0,857 arasında değerler 
almıştır. Yapılan analizde ölçeğin toplam varyansın \%64,581’ini açıklamıştır. Güvenilirliğe ilişkin analizde hastayken işe gelme (presenteeism) değişkeninin Cronbach Alfa güvenilirlik katsayısının 0.886 olduğu görülmüştür.

\section{Hipotezlerin Testi}

Analizler gerçekleştirilmeden önce elde edilen verilerin normal dağılıma uygunluğu test edilmiştir. Normal dağılım göstermeyen verilerle yapılan analizlerin yanıltıcı sonuçları ortaya çıkarması muhtemeldir. Bu türden bir hatayla karşılaşmamak için verilerin normal dağılıma uyup uymadığı test edilmiş olup analiz sonuçları verilerin normal dağılıma uygun olmadığını göstermiştir. Bu doğrultuda örgütsel adalet alg1sı ve hastayken işe gelme (presenteeism) davranışı arasındaki ilişki spearman korelasyon analiziyle tespit edilmiş bulgular Tablo 4'de verilmiştir.

Tablo 4.Değiskkenler Arasindaki Korelasyonlar

\begin{tabular}{|c|c|c|c|c|c|c|c|}
\hline Faktörler & $\overline{\bar{X}}$ & $S S$ & 1 & 2 & 3 & 4 & 5 \\
\hline 1-Dağıtım Adaleti & 3,086 & 1,028 & 1 & & & & \\
\hline 2-Prosedür Adaleti & 3,015 & ,962 &, $658^{* *}$ & 1 & & & \\
\hline 3-Etkileşim Adaleti & 3,381 & ,896 &, $665^{* *}$ &, $770^{* *}$ & 1 & & \\
\hline 4-Örgütsel Adalet & 3,207 &, 858 &, $851^{* *}$ &, $898^{* *}$ &, $914^{* *}$ & 1 & \\
\hline $\begin{array}{l}\text { 5-Hastayken İşe Gelme } \\
\text { (presenteeism) }\end{array}$ & 3,434 & ,879 &, $426^{* *}$ &, $407^{* *}$ &, $476^{* *}$ &, $495^{* *}$ & 1 \\
\hline
\end{tabular}

Tablo 4'te görüldüğü gibi örgütsel adaletin dağıtım adaleti, prosedür adaleti ve etkileşim adaleti boyutlarının her biri ile hastayken işe gelme (presenteeism) değişkeni arasında doğru yönlü \%99 önem düzeyinde anlamlı bir ilişki vardır. Bu ilişkinin düzeyi incelendiğinde ise Hastayken işe gelme (presenteeism) ile dağıtım adaleti $(0,426)$ ve prosedür adaleti $(0,407)$ arasında orta düzeyde; etkileşim adaletinin ise güçlü $(0,495)$ ilişkisinin olduğu sonucuna varılabilir. Bütün olarak bakıldığında ise örgütsel adalet alg1sı ile hastayken işe gelme (presenteeism) davranışı arasında doğru yönlü ve güçlü $(0,495)$ düzeyde bir ilişkinin var olduğu ifade edilebilir. Bu doğrultuda adalet algısı yüksek olan çalışanların hastayken işe gelme (presenteeism) davranış1 sergilemeleri beklenmektedir.

Korelâsyon analizi ile değişkenler arasında ilişkinin var olduğu saptandıktan sonra, çalışmanın amacına uygun olarak regresyon analizi yapılmış ve sonuçlar aşağıdaki Tablo 5'de özetlenmiştir.

Tablo 5. Değiskeenlere Yönelik Yapılan Regresyon Analiz̨i Sonuçar

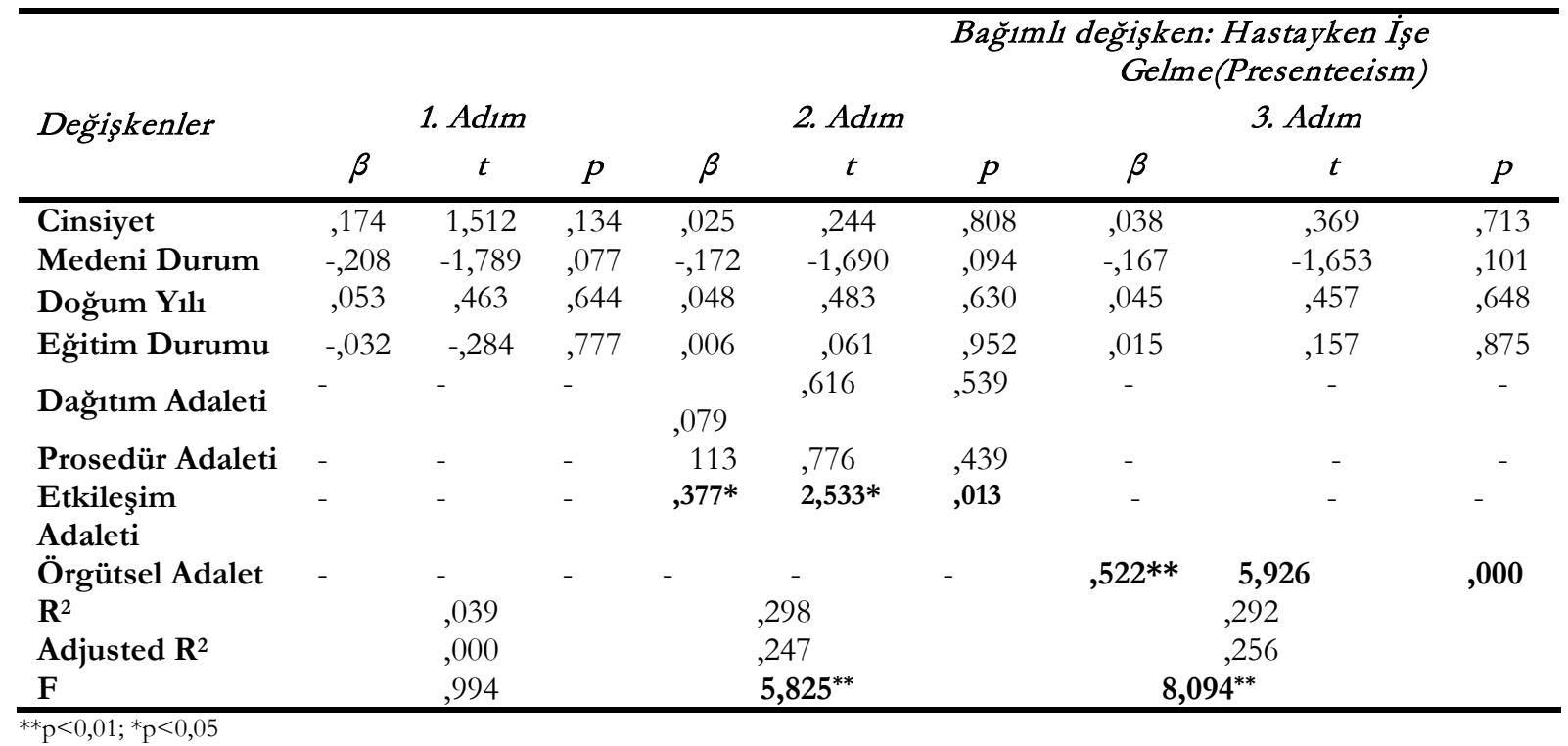

Tablo 5'teki araştırma hipotezlerinin geçerliliğine ilişkin sonuçlara bakıldı̆̆ında; sadece örgütsel adaletin boyutlarından olan etkileşim adaleti ile hastayken işe gelme (presenteeism) arasındaki etki düzeyini gösteren beta katsayısı $(\beta=, 377$ ve $\mathrm{p}=$,013) anlamlı bulunmuştur. Dolayısıyla etkileşim adaleti algısı, 
hastayken işe gelme (presenteeism) değişkenini olumlu yönde etkilemiş, H1c desteklenmiştir. Diğer taraftan örgütsel adalet algısının diğer boyutları olan dağıtım adaleti ve prosedür adaletinin, hastayken işe gelme (presenteeism) davranışını etkilediğini öne süren H1a ve H1b kabul edilmemiştir.

Tablo incelendiğinde ayrıca bir bütün olarak örgütsel adalet algısının hastayken işe gelme (presenteeism) üzerindeki etkisini gösteren beta katsayısının da anlamlı $(\beta=, 522$ ve $p=, 000)$ olduğu görülmüştür. Başka bir ifadeyle örgütsel adalet algısı, hastayken işe gelme (presenteeism) davranışını olumlu yönde etkilemiştir. Böylelikle H1 desteklenmiştir.

\section{Genel Değerlendirme ve Sonuç}

Çalışanların örgütlerine yönelik sahip oldukları adalet algısı verimliliği etkileyen faktörlerden birisidir. Adalet algısı kaynakların dağıtımına, dağıtıma ilişkin süreçlere ve kurulan etkileşimlere göre farklılaşabilmektedir. Diğer taraftan çalışanların hastayken dahi işe gelme istekliliğini ifade eden hastayken işe gelme (presenteeism) kavramı, iş güvensizliğinden ya da aşırı iş tutkusundan kaynaklanabilmektedir (Lowe, 2002). Bu noktada çalışanların örgütlerine yönelik adalet algılarının, hastayken işe gelme (presenteeism) düzeyleri üzerinde bir etkiye sahip olup olmadığını öğrenmek çalısmamızın temel amacını oluşturmaktadır.

Araştırma sonucuna göre bir bütün olarak çalışanların örgütsel adalet algılarının, hastayken işe gelme (presenteeism) davranışı üzerinde olumlu bir etkiye sahip olduğu görülmektedir. Başka bir ifadeyle örgütsel adalet algısı yüksek olan çalışanlar bir anlamda özveri göstererek hasta olsalar dahi işe gitme davranışı sergileme eğilimindedirler. Elde edilen bu bulgu Akdoğan, Harmanc1 ve Bayram'ın (2018) araştırma bulgularını desteklemektedir. Örgütsel adaletin alt boyutları olan prosedür adaleti, etkileşim adaleti ve dağıtım adaletinin hastayken işe gelme (presenteeism) üzerindeki etkisine bakıldı̆̆ında ise bu boyutlardan yalnızca etkileşim adaleti algısının, hastayken işe gelme (presenteeism) davranışı üzerinde olumlu bir etkisi olduğu sonucu ortaya çıkmaktadır. Bu bulgu hastayken işe gelme davranışının sergilenmesinde çalışanların yöneticileri ile etkileşime ilişkin adalet algısına baktıkları, bir diğer ifadeyle etkileşime ilişkin adalet algısının hastayken işe gelme davranışının belirleyicisi olduğu anlamına gelmektedir. Başka bir ifadeyle çalışanların örgüte fayda sağlama düşüncesiyle hastayken işe devam etme arzuları, algıladıkları adalet seviyesine bağlıdır. Kendilerine adil davranıldığını düşünen çalışanlar örgütlerine adanmakta ve bunun sonucunda içerisinde bulundukları durum ne kadar kötü de olsa öncelikli hedefleri örgütsel çıktılar olmaktadır.

Araştırmamızda genel olarak örgütlerinin kendilerine adil davrandığını algılayan çalışanların hastayken işe gelmeyi tercih ettikleri görülmüsstür. Bu sonucun nedeninin örgüt kültürü, daha kapsayıcı olarak ise ulusal kültür ile ilişkili olduğu ifade edilebilir. Hofstede (1980) ulusal kültürler sinıflandırmasında ülkemizi toplulukçu kültürler arasında ifade etmektedir. Toplulukçu kültürlerde yaşayan insanlar bireysel çıkarlardan ziyade grup çıkarını ön plana almaktadırlar. Bu açıdan çalışanlar hasta iken işe gitmediklerinde yapmaları gereken işlerin diğer çalışma arkadaşlarına yükleneceğini düşünebilirler. Dolayısıyla çalışanlar hasta iken bile işe gitmeyi tercih edebilirler (Akdoğan vd., 2018). Ayrıca çalışanların örgütlerini adil olarak algılamaları örgütlerine yönelik sadakat ve bağlllık duygularını da beslemekte ve bu durum çalışanları hasta iken dahi iş yerine giderek örgüte bir fayda sağlama düşüncesini sevk etmektedir.

Yapılan çalışmanın bir dizi kısıtı da bulunmaktadır. Bu kısıtların başında, çalışma örnekleminin sadece kamuda görev yapan ve ofis içerisinde çalışan kişilerden oluşması gelmektedir. İleride yapılacak çalışmalarda örneklemin özel sektörde ve evden ofise bağlanarak çalşan kişileri kapsayacak şekilde genişletilmesi önerilebilir.

\section{Kaynakça}

Adams, J. S. (1965). Inequity in Social Exchange. In L. Berkowitz (Ed.), Advances in Experimental Social Psychology, 2, 267-299. New York: AcademicPress.

Akdoğan, A. A., Harmanc1, Y. K. ve Bayram, A. (2018). Algılanan Örgütsel Adalet ve İşte Var Olamama (Presenteeism) İlişkisinde Stresin Aracı Rolü. Manas Sosyal Araștrmalar Dergisi, 7(2), 197-211.

Aronsson, G.,Gustafsson, K. ve Dallner, M. (2000). Sick But yet at Work. An EmpiricalStudy of SicknessPresenteeism. Journal of Epidemiol Community Health, 54, 502-509.

Atlaş, S. S. ve Çekmecelioğlu, H. G. (2015). Örgütsel Adalet Algisının İș Tatmini, Örgütsel Bağlllık ve İş Performansı Üzerindeki Etkileri: Okul Öncesi Öğretmenleri Üzerinde Bir Araştırma. Atatürk Üniversitesi İktisadi ve İdari Bilimler Dergisi, 29(3), 421-439. 
Bakan, İ., Güler, B. ve Kara, E. (2017). Örgütsel Demokrasinin Örgütsel Adalet ve Örgütsel Destek Alg1lar1 Üzerine Etkileri: Otel Çalışanlarına Yönelik Bir Araştırma. Süleyman Demirel Üniversitesi İktisadi ve İdari Bilimler Fakültesi Dergisi, 22(4), 1031-1048.

Baysal, İ.A., Baysal, G., Aksu, G. ve Aksu, N. (2014). Presenteeism (İşte Varolmama Sorunu) İle Örgütsel Bağlll1k Arasındaki İlişki: Adnan Menderes Üniversitesi Akademik Personeli Üzerinde Bir Uygulama. Electronic Journal of Vocational Colleges, Ağustos, 134-152.

Cohen- Charash, Y. ve Spector, P. E. (2001). The Role of Justice in Organizations: A Meta-Analysis. Organizational Behavior and Human Decision Processes, 86(2), 278-321.

Colquitt, J. A.,Conlon, D. E., Wesson, M. J., Porter, C. O. L. H. ve Ng, K. Y. (2001). Justice at the Millennium: A Meta-AnalyticReview of 25 Years of OrganizationalJusticeResearch. Journal of Applied Psychology, 86(3): 425-445.

Cropanzano, R.,Bowen D. E. ve Gilliland S. W. (2007). The Management of Organizational Justice. Academy of Management Perspectives, November, 34-48.

Conway, P. M, Clausen, T.,Hansen, A.M. ve Hogh, A. (2016). Workplace Bullying and Sickness Presenteeism: CrossSectional and Prospective Associations in a 2-Year Follow-Up Study. International Archives of Occupational Environmental Health, 89, 103-114.

Çağlıyan, V. Attar, M. ve Derra, M. El N. (2017). The Relationship Between Organizational Justice Perception and Organizational Commitment: A Study on Doğuş Otomotiv Authorized Dealers in Konya, Süleyman Demirel Üniversitesi İktisadi ve İdari Bilimler Fakültesi Dergisi, 22(2), 599-612.

Çetin, M. (2016). An Exploratory Study of Presenteeism in Turkish Context. Emerging Markets Journal, 6(1), 24-38.

Çiftçi, B. (2010). İşte Var Ol(Ama)Ma Sorunu ve İşletmelerin Uygulayabileceği Çözüm Önerileri. Çalısma ve Toplum, 2010(1), 153-174.

Dew, K., Keefe, V. ve Small, K. (2005). Choosing to Work When Sick: Workplace Presenteeism. Social Science \& Medicine, 60, 2273-2282.

Demirbulat, Ö.G. ve Bozok, D. (2015). Presenteeism (İşte Varolamama) ile Yaşam Doyumu, Fiziksel ve Ruhsal İyilik Halinin Etkileşimine Yönelik Seyahat Acentası İsgörrenleri Üzerinde Bir Araştırma. KMÜ Sosyal ve Ekonomik Arasttrmalar Dergisi, 16(27), 7-13.

Demirgil, Z. ve Mücevher, M. H. (2017). Meslek Yüksekokullarında Presenteeism: İdari ve Akademik Personel Üzerine Karșılaştırmalı Bir Analiz. Mehmet Akif Ersoy Üniversitesi Sosyal Bilimler Enstitüsü Dergisi, 9(21), 237-253.

Greenberg, J. (1990). Organizational Justice: Yesterday, Today, and Tomorrow. Journal of Management, 16(2), $399-432$.

Güzel, B. ve Ayazlar, G. (2014). Örgütsel Adaletin Örgütsel Sinizm ve İşten Ayrılma Niyetine Etkisi: Otel İşletmeleri Araştırması. KMÜ Sosyal ve Ekonomik. Arasttrmalar Dergisi, 16(26), 133-142.

Hemp, P. (2004). Presenteeism: At Work-But Out of It. Harvard Business Review, 82, 49-58.

Hofstede, G. (1980). Culture's Consequences: International Differences in Work-Related Values, Sage Publications, 1980, 1327.

Johns, G. (2010). Presenteeism in theWorkplace: A Review and Research Agenda. Journal of Organizational Behavior, 31, 519-542.

Lowe, G. (2002). Here in Body, Absent in Productivity: Presenteeism Hurts Output, Quality of Work-Life andEmployeeHealth. Canadian HR Reporter: The National Journal of Human Resource Management, 1-2.

Lyu, X. (2016). Effect of Organizational Justice on Work Engagement With Psychological Safety as A Mediator: Evidence From China, Social Behavior and Personality, 44(8), 1359-1370.

Koopman, C., Pelletier, K.R., Murray, J.F., Sharda, C.E., Berger, M.L., Turpin, R.S., Hackleman, P., Gibson, P. Holmes, D.M. ve Bendel, T. (2002). Stanford Presenteeism Scale: Health Statusand Employee Productivity. JOEM, 44(1), 14-20.

Niehoff, B. P. ve Moorman, R. H. (1993). Justice as a Mediator of the Relationship Between Methods of Monitoring and Organizational Citizenship Behavior. Academy of Management Journal, 36(3), 527-556.

Prater, T. ve Smith, K. (2011). Underlying Factors Contributing to Presenteeism and Absenteeism. Journal of Business \&Economics Research, 9(6), 1-14.

Rajabi, M., Abdar, Z. E. ve Agoush, L. (2017). Organizational Justice and Trust Perceptions: A Comparison of Nurses in Publicand Private Hospitals. Middle East Journal of Family Medicine, 15(8), 205-211.

Samanc1, S. ve Basım, H. N. (2018). Akademisyenlerin Örgütsel Adalet Alg1ları ve Örgütsel Vatandaşlık Davranışları: Psikolojik Sermayenin Aracilık Rolü. Business and Economics Research Journal, 9(2), 363-380.

Yıldız, S. (2014). Örgütsel Adaletin Örgütsel Vatandaşlık Davranışına Etkisinde İş Tatmininin Aracı Rolü. Ege Akademik Bakus, 14(2), 199-210.

\section{EXTENDED ABSTRACT}

In this study, the concepts of organizational justice and presenteeism behavior are discussed. Organizational justice refers to being fair in the processes and practices within the organization (Colquitt et al., 2001). Presenteeism is defined as the continuation of the work of the employees even though they are ill or have health complaints (Aronsson et al., 2000). There are reasons why employees continue to work despite being sick, such as fear of losing their jobs and strong commitment. In this study, it was thought that one of the reasons underlying this behavior might be the perception of organizational justice. 
For this reason, the effect of organizational justice perception on presenteeism behavior was investigated in this study. When the literature on the subject is examined, it is seen that the studies dealing with the relationship between organizational justice and presenteeism behavior are very limited. On the subject, Akdoğan, Harmancı and Bayram (2018) modeled that perception of justice affects presenteeism behavior through occupational stress. In this study conducted on blue collar in different businesses, it was seen that organizational justice had a positive effect on presenteeism. The following hypothesis (s) is tried to be tested with reference to this study finding:

\section{H1: Public employees' perceptions of organizational justice positively affect presenteeism behaviors.}

H1 a: Public employees' perceptions of distribution justice positively affect presenteeism behaviors.

H1b: Public employees' perceptions of procedural justice positively affect presenteeism behaviors.

\section{H1c: Public employees' perceptions of interaction justice positively affect presenteeism behaviors.}

This study aimed to determine the effect of organizational justice on presenteeism behavior. The population of the research was composed of 140 employees working in a public institution in Siirt province. Of the 110 questionnaires sent to employees (by hand and by e-mail), 104 were returned without error and complete (return rate 94.5\%). Therefore, analyzes were conducted on 104 questionnaires.

In the research, before the hypothesis tests were made, the suitability of the data to the normal distribution was tested. Analysis results showed that the data was not suitable for normal distribution. Therefore, the relationship between the concepts was determined by Spearman Correlation analysis. Correlation findings showed that there were a positive relationship between distribution justice and presenteeism; procedural justice and presenteeism; and interaction justice and presenteeism.

After correlation analysis, regression analysis was performed in accordance with the aim of the study. Regression analysis findings showed that only beta coefficient showing the effect level between interaction justice dimension and presenteeism $(\beta=, 377$ and $p=, 013)$ is significant. Therefore, the perception of interaction justice positively effected the presenteeism variable and $\mathrm{H} 1 \mathrm{c}$ was supported. At the same time, the beta coefficient showing the effect of organizational justice perception on presenteeism was also meaningful $(\beta=, 522$ and $p=, 000)$. In other words, the perception of organizational justice positively effected presenteeism behavior. Thus, H1 was supported.

According to the results of the study, it was seen that employees' perceptions of organizational justice had a positive effect on presenteeism behavior. In other words, employees who have a high perception of organizational justice tend to exhibit self-sacrifice in a sense and go to work even if they are sick. This finding supported the findings of the study conducted by Akdoğan et al. (2018). At the dimensional level, it was concluded that the interaction justice dimension had a positive effect on presenteeism behavior. This finding means that employees look at the perception of justice regarding interaction with their managers for presenteeism behavior. In other words, the finding means that the perception of justice related to the interaction is the determinant of presenteeism behavior.

In our study, it was seen that employees who perceived fair treatment in the organization generally preferred to come to work even if they got sick (presenteeism). It can be said that the reason for this result is related to organizational culture and more comprehensively to national culture. Turkey has a collectivistic culture. People living in collectivist cultures care more about group interests than individual interests. In this respect, employees think that when they get sick and do not come to work, the work they need to do will be attributed to other colleagues. Therefore, employees may choose to go to work even when they are sick (Akdoğan et al., 2018). In addition, employees' perception of justice in their organizations feeds their sense of loyalty and commitment towards their organizations and this situation encourages the idea of providing benefit to the organization by going to work even when they get sick. 